\title{
Kinetic, equilibrium and thermodynamic modelling of the sorption of metals from aqueous solution by a silica polyamine composite
}

\author{
H Tutu' ${ }^{1 *}$ E Bakatula1', S Dlamini' ${ }^{1}$ E Rosenberg ${ }^{2}$, V Kailasam² and EM Cukrowska' \\ University of the Witwatersrand, School of Chemistry, Private Bag X3, WITS 2050, Johannesburg, South Africa \\ ${ }^{2}$ University of Montana, Department of Chemistry and Biology, Missoula, MT 59812, USA
}

\begin{abstract}
Batch sorption studies were conducted to assess the potential of a phosphonated silica polyamine composite (BPAP) to remove metals ( $\mathrm{Co}, \mathrm{Cu}, \mathrm{Fe}, \mathrm{Mg}, \mathrm{Mn}, \mathrm{Ni}, \mathrm{U}$ and $\mathrm{Zn}$ ) from mine waters. The metal adsorption showed a good Langmuir isotherm fit. $\mathrm{Ni}$ and $\mathrm{Mn}$ fitted both the Freundlich and Langmuir isotherms. The activation energies $(E a)$ of $\mathrm{Co}, \mathrm{Mg}$ and $\mathrm{Ni}$ ranged between 5 and $40 \mathrm{~kJ} \cdot \mathrm{mol}^{-1}$, signifying physisorption while $\mathrm{U}$ showed a chemisorption type of adsorption (with $E a$ $>50 \mathrm{~kJ} \cdot \mathrm{mol}^{-1}$ ). $\mathrm{Cu}$ and $\mathrm{Fe}$ on the other hand gave negative $E a$ values, indicating their preference to bind to low-energy sites. The pseudo-second-order kinetic model provided the best correlation of the experimental data, except for $\mathrm{Mg}$ and $\mathrm{Ni}$ for which the pseudo-first-order model and the Elovich model gave a better fit, respectively. Adsorption was almost constant over a wide $\mathrm{pH}$ regime and increased with time. Adsorption increased with concentration of the metals with the exception of $\mathrm{Co}$, Fe and Ni which displayed about a $40 \%$ drop at a concentration of $200 \mathrm{mg} \cdot \ell^{-1}$. Desorption experimental data gave poor results except for $\mathrm{U}$ which showed $99.9 \%$ desorption.
\end{abstract}

Keywords: silica polyamine composite, sorption, kinetics, isotherms, desorption

\section{INTRODUCTION}

The presence of trace metals in aquatic systems is of concern because of their toxicity and non-biodegradable nature. The sources of metals in the environment include sewage, mining, agricultural and industrial activities, with mining accounting for the larger proportion. Mining of certain minerals, including gold, copper, and nickel, is associated with acid mine drainage (AMD) problems that cause long-term impairment to waterways and biodiversity (Akcil and Koldas, 2006). There are several existing methods for the treatment of AMD, depending upon the volume of effluent, and the type and concentration of contaminants present (Chander and Mohan, 2001). These include chemical treatment (e.g. oxidation and neutralisation by lime), phytoremediation (i.e. phytoextraction, phytovolatilisation and phytostabilisation), ion exchange (e.g. use of activated carbon), polymers and biosorption, among others. There are some drawbacks associated with most of these methods: e.g., neutralisation leads to the formation of metal-containing solid waste that poses disposal problems; slow rates of biomass production in phytoremediation (Jiang et al., 2009); polymer adsorbents tend to have low selectivity of the metals and often swell and shrink due to their elastic nature.

This study presents a silica-based polyamine composite, namely BPAP, as an alternative material for the adsorption of metals from acidic mine leachates and wastewaters. Generally, silica-based composites have polyamine chelating ligands which are bound to the silica gel layer covalently. The polyamine chelating ligands can be further modified with metalselective functional groups, which is an advantage of these composites. In the case of BPAP, the Mannich reaction was

To whom all correspondence should be addressed. 용 +27 11717 6771; e-mail: hlanganani.tutu@wits.ac.za Received 22 March 2012; accepted in revised form 24 June 2013. used to convert the polyamine composite to an amino phosphonic acid-functionalised composite which has been used to immobilise high valent metals (Fig. 1) (Rosenberg et al., 2006). These materials do not shrink or swell; can be used at high temperatures (up to $110^{\circ} \mathrm{C}$ ); have improved stability with regard to radiolytic decomposition; and have an elongated usable lifetime, unlike their polymer counterparts (Kailasam et al., 2009). The polar nature of their surfaces also makes for better masstransfer kinetics in aqueous solutions. This study focused on the kinetic, equilibrium and thermodynamic processes related to metal sorption on BPAP, using metals commonly found in AMD.

Kinetics of metal ion sorption governs the rate, which determines the residence time and is one of the important characteristics defining the efficiency of an adsorbent (Kaur et al., 2012). The kinetic models used included the pseudo-firstorder model, the pseudo-second-order model, the intraparticle diffusion model and the Elovich model.

The pseudo-first-order equation (Lagergren, 1898) has been widely used by many other researchers to study the kinetics of heavy metal adsorption (Qiu et al., 2009). The model has the following form:

$$
\frac{d q z}{d t}=k_{1}\left(q_{e}-q_{t}\right)
$$

where:

$q_{e}$ and $q_{t}$ are the amount of metal ions adsorbed $\left(\mathrm{mg} \cdot \mathrm{g}^{-1}\right)$ at equilibrium and at any time $t$, respectively

$k_{1}$ is the rate constant $\left(\mathrm{min}^{-1}\right)$ of pseudo-first-order adsorption.

By applying the boundary conditions $t=0$ to $t=t$ and $q_{t}=0$ to $q_{t}=q_{t}$, the integration form is given by the equation below:

$$
\log \left(q_{e}-q_{t}\right)=\log \left(q_{e}\right)-\frac{k_{\mathrm{A}}}{2.303} t
$$


The plot of $\log \left(q_{e}-q\right)$ vs $t$ should give a linear relationship from which $k_{1}$ and $q_{e}$ can be determined from the slope and intercept of the plot, respectively.

The pseudo second-order equation is expressed as (Ho et al., 1999):

$$
\frac{d q \underline{t}}{d t}=k_{2}\left(q_{e}-q_{t}\right)^{2}
$$

where:

$k_{2}$ is the rate constant of the pseudo second-order adsorption $\left(\mathrm{gm} \cdot \mathrm{g}^{-1} \cdot \mathrm{min}^{-1}\right)$

For the boundary conditions $t=0$ to $t=t$ and $q_{t}=0$ to $q_{t}=q_{t}$, the integrated form of Eq. (2) becomes:

$$
\frac{1}{\left(a_{e}-a_{t}\right)}=\frac{1}{q_{e}}+k t
$$

The linear form of Eq. (3) is given by the following equation:

$$
\frac{t}{q_{t}}=\frac{1}{k_{2} q_{e^{2}}}+\frac{1}{q_{g}}(t)
$$

If the pseudo-second-order is applicable, the plot $t / q_{t}$ vs $t$ should give a straight line. $q_{e}$ and $k_{2}$ may be determined from the slope and intercept of the plot, respectively.

The Elovich model describes the chemical nature of the adsorption and is generally expressed as (Günay et al., 2007):

$$
\frac{d q_{t}}{d t}=\alpha \exp \left(-6 q_{t}\right)
$$

where:

$\alpha$ is the initial adsorption rate $\left(\mathrm{mg} \cdot \mathrm{g}^{-1} \cdot \mathrm{min}^{-1}\right)$ and

$\beta$ is the Elovich constant related to the surface coverage $\left(\mathrm{g} \cdot \mathrm{mg}^{-1}\right)$

By applying the boundary conditions $q_{t}=0$ at $t=0$ and $q_{t}=q_{t}$ at $t=t$, the integrated form of Eq. (6) is:

$$
q_{t}=\frac{1}{\beta} \ln (\alpha \beta)+\frac{1}{\beta} \ln (t)
$$

The plot of $q_{t} \mathrm{vs} \ln (t)$ should yield a linear relationship with a slope of $(1 / \beta)$ and an intercept of $(1 / \beta) \ln (\alpha \beta)$.

The intraparticle diffusion model is characterised by a linear relationship between the amount adsorbed at time $t\left(q_{t}\right)$ and the square root of the time, and is expressed as (Allen et al., 1989):

$$
q_{t}=k_{i d} t^{1 / 2}+C
$$

where:

$$
\begin{aligned}
& q_{t} \text { is the amount of metal ion adsorbed at time } t \text { (min) } \\
& \text { expressed }\left(\mathrm{mg}^{-1}\right), k_{i d} \text { is the initial rate constant } \\
& \left(\mathrm{mg} \cdot \mathrm{g}^{-1} \cdot \mathrm{min}^{-1 / 2}\right) \text { of intraparticle diffusion, } \\
& t \text { is the time of sorption duration (min), and } \\
& C \text { gives information about the boundary layer } \\
& \text { thickness }
\end{aligned}
$$

A normalised standard deviation $(\Delta q)$ was used in order to compare the validity of each model. $\Delta \mathrm{q}(\%)$ is calculated by the following expression (Wang et al., 2007):

$$
\Delta q(\%)=100 \cdot \sqrt{\frac{\sum_{i=1}^{n}\left(\frac{q_{\exp }-q_{c a l}}{q_{\exp }}\right)^{2}}{n-1}}
$$

where:

$$
q_{\text {exp }} \text { is the experimental metal ion uptake }
$$

$q_{\text {cal }}$ the calculated amount of metal ions adsorbed and $n$ is the number of data points

The goodness-of-fit of the models to the experimental data was controlled by comparison of the correlation coefficients $R$ and standard errors $S$. The CurveExpert 1.3 program was used to fit the experimental data with the confidence level set at $95 \%$.

Adsorption equilibria provide fundamental physicochemical data for evaluating the applicability of the adsorption process as a unit operation (Srivastava and Rupainwar, 2011). In this study, the Langmuir and Freundlich isotherms expressions were used for the anaysis of the equilibrium data.

The linear form of the Langmuir equation is:

$$
\frac{c_{g}}{q_{g}}=\frac{1}{q_{0} k_{L}}+\frac{q_{R}}{q_{0}}
$$

where:

$q_{e}\left(\mathrm{mg} \cdot \mathrm{g}^{-1}\right)$ is the equilibrium adsorption capacity,

$K_{L}$ is a constant related to the energy of adsorption,

$C_{e}\left(\mathrm{mg} \cdot \ell^{-1}\right)$ is the concentration at equilibrium and

$q_{o}\left(\mathrm{mg}^{-1}\right)$ is the maximum amount adsorbed required to saturate a unit mass of adsorbent.

$b$ and $q_{o}$ are obtained from the slope of the plot $C_{e} / q_{e}$ versus $C_{e}$

A good fit of this equation reflects monolayer adsorption (Teng and Hsieh, 1998).

The Freundlich model is as follows:

$$
q_{e}=K_{f}\left(C_{e}\right)^{1 / n}
$$

where:

$K_{\mathrm{f}}$ and $n$ are equilibrium constants indicative of adsorption capacity and adsorption intensity, respectively (Cozmuta et al., 2012; Teng and Hsieh, 1998)

The linearised form of the Freundlich equation can be used:

$$
\log q_{e}=\log K_{f}+1 / n \log C_{e}
$$

where:

$C_{e}$ is the equilibrium phase ion concentration $\left(\mathrm{mg} \cdot \ell^{-1}\right)$ and $q_{e}$ is the adsorption capacity at equilibrium $\left(\mathrm{mg}^{-\mathrm{g}^{-1}}\right)$

The $n$ and $K_{f}$ values can be obtained from the slopes and intercepts of the isotherm. If the value of $n$ is between 1 and 10, this refers to a beneficial isotherm. The linear regression analysis was carried out with the CurveExpert 1.3.

Zheng et al. (2009) stated that the essential characteristics of a Langmuir isotherm can be expressed in terms of a dimensionless separation factor, $R s$, which is defined by the following equation:

$$
R_{S}=\frac{1}{1+\pi \Gamma_{0}}
$$

where:

$a$ is the Langmuir constant,

$C_{o}$ is the initial concentration $\left(\mathrm{mg} \cdot \ell^{-1}\right)$,

$R_{s}^{o}$ indicates the shape of the isotherm as follows:

$R_{\mathrm{s}}>1$ Unfavourable

$R_{s}^{s}=1$ Linear

$0<R_{s}<1$ Favourable

$R_{s}=0$ Irreversible 


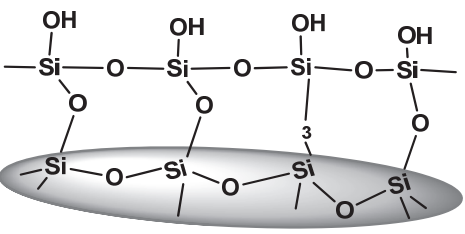

Acid washed and Humidified Silica

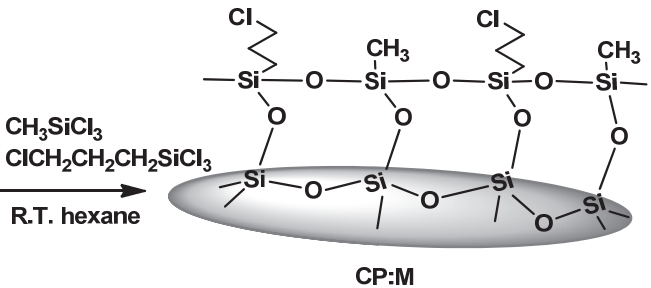

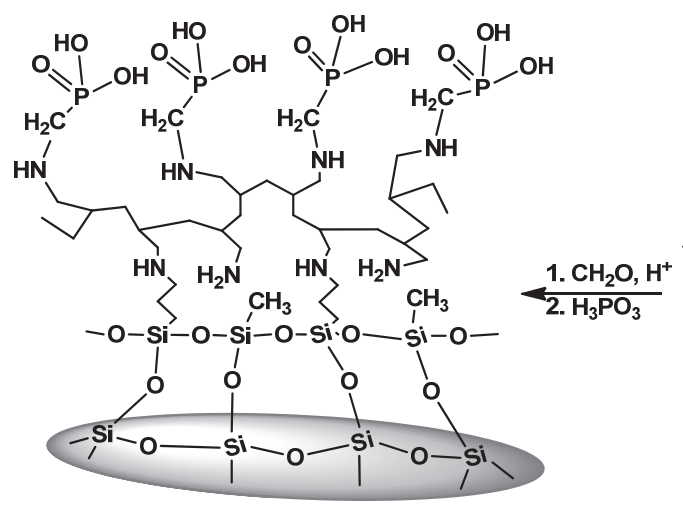

BPAP
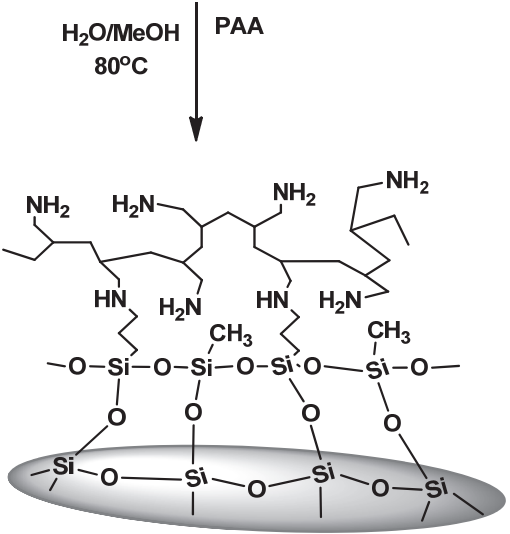

BP-1
Figure 1

Schematic diagram of the synthesis of BPAP material (Rosenberg et al., 2006; Kailasam et al., 2009; Weber and Chakarvorti, 1974)

\section{EXPERIMENTAL PROTOCOL}

\section{Materials}

\section{Synthesis of BPAP by the Mannich Reaction}

The silica polyamine composite BP-1 is first synthesised and used as a precursor for making BPAP. The synthesis of BPAP is mentioned in detail in other work by co-authors of this study (Rosenberg et al., 2006; Kailasam et al., 2009). $10 \mathrm{~g}$ of BP-1 was mixed with a reagent solution of $30 \mathrm{m \ell}$ of $2 \mathrm{~mol} \cdot \ell^{-1} \mathrm{HCl}$ and $10 \mathrm{~g}$ of phosphonic acid $\left(\mathrm{H}_{3} \mathrm{PO}_{3}\right)$ in a $250 \mathrm{ml}$ flask equipped with an overhead stirrer. The flask was heated to $95^{\circ} \mathrm{C}$, and $9 \mathrm{ml}$ of formaldehyde $\left(\mathrm{CH}_{2} \mathrm{O}\right)$ solution $(37.7 \%)$ was gradually added with stirring. The reaction mixture was heated at $95^{\circ} \mathrm{C}$ for $24 \mathrm{~h}$. The flask was cooled and the product was filtered. The resulting composite was washed three times with $40 \mathrm{~m} \ell$ of deionised water; once with $40 \mathrm{~m} \ell$ of $1 \mathrm{~mol} \cdot \ell^{-1} \mathrm{NaOH}$; three times with $40 \mathrm{~m} \ell$ of deionised water; once with $40 \mathrm{~m} \ell$ of $0.5 \mathrm{~mol} \cdot \ell^{-1} \mathrm{H}_{2} \mathrm{SO}_{4}$; two more times with $40 \mathrm{~m} \ell$ of deionised water; twice with $40 \mathrm{ml}$ of methanol; and dried to a constant mass at $65^{\circ} \mathrm{C}$. A mass gain of $20 \%$ and $22 \%$ was obtained starting with BP-1.

The elemental composition of the BPAP made from BP-1 is $14.20 \% \mathrm{C}, 3.03 \% \mathrm{H}, 3.36 \% \mathrm{~N}, 4.34 \% \mathrm{P}$ (Kailasam et al., 2009; Hughes et al., 2006).

\section{Adsorption studies}

Reagents used for the sorption studies were of analytical grade. Standards used for quantification were of high purity and were obtained from Merck, South Africa. The metal ion solutions $\left(\mathrm{Co}^{2+}, \mathrm{Cu}^{2+}, \mathrm{Fe}^{2+}, \mathrm{Mg}^{2+}, \mathrm{Mn}^{2+}, \mathrm{Ni}^{2+}, \mathrm{U}^{6+}\left(\mathrm{as} \mathrm{UO}_{2}{ }^{2+}\right)\right.$ and $\left.\mathrm{Zn}^{2+}\right)$ were prepared by weighing appropriate amounts of the nitrate salts to make $1000 \mathrm{mg} \cdot \ell^{-1}$ stock solutions. Appropriate aliquots were taken from these standards for subsequent dilution to the desired concentration level. Adsorption for single-component solutions was done using an optimised solid: solution ratio of 1:50.
The effect of $\mathrm{pH}$ on adsorption was assessed over the $\mathrm{pH}$ range 2-10 and the thermodynamic parameters were calculated at $18^{\circ} \mathrm{C}$ and $30^{\circ} \mathrm{C}$. The effects of metal concentrations were assessed in the range $10-200 \mathrm{mg} \cdot \ell^{-1}$ while contact time was in the range $0-180 \mathrm{~min}$. The metal ion concentrations were measured using a Genesis Inductively Coupled Plasma Optical Emission Spectrometer (ICP-OES) (Spectro, Kleve, Germany).

The adsorption capacity was calculated using the general equation:

$$
q_{e}=\frac{\left(C_{D}-C_{t}\right) V}{M}
$$

where:

$q_{\mathrm{e}}$ is the amount of metal ions adsorbed ( $\left.\mathrm{mg} \mathrm{g}^{-1}\right)$,

$C_{o}$ and $C_{t}$ are metal ion concentrations in solution before and after adsorption $\left(\mathrm{mg} \cdot \ell^{-1}\right)$,

$V$ the volume of the medium $(\ell)$, and

$M$ the amount of BPAP used in the reaction mixture $(\mathrm{g})$

\section{Desorption studies}

Batch desorption tests of metals (regeneration of BPAP) were conducted using $\mathrm{H}_{2} \mathrm{SO}_{4}$, ethylene diamine tetraacetic acid (EDTA) and $\mathrm{Na}_{2} \mathrm{CO}_{3}$ with concentrations ranging from 0.1-3.0 mol $\cdot \ell^{-1}$ with $1.0 \mathrm{~g}$ of BPAP sorbent containing the desired concentration of metal ions. The mixture was agitated in $250 \mathrm{~m} \ell$ bottles at $150 \mathrm{r} \cdot \mathrm{min}^{-1}$ for $12 \mathrm{~h}$ using a mechanical automated shaker. The solution was then filtered using Whatman No. 41 filter paper. The concentration of the metal ions in the filtrate was measured using ICP-OES.

\section{RESULTS AND DISCUSSION}

\section{Effect of $\mathrm{pH}$}

The results for the effect of $\mathrm{pH}$ on metal adsorption are shown in Fig. 2. Adsorption was based on a solution containing $5 \mathrm{mg} \cdot \ell^{-1}$ of each metal. 


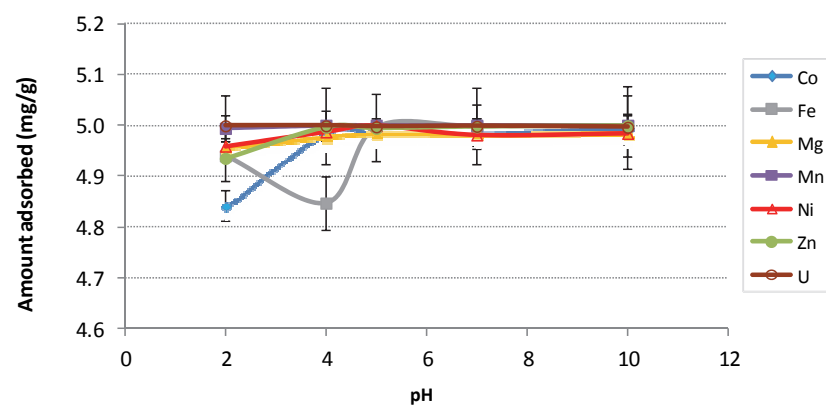

Figure 2

Dependence of metal ion adsorption on $\mathrm{pH}$

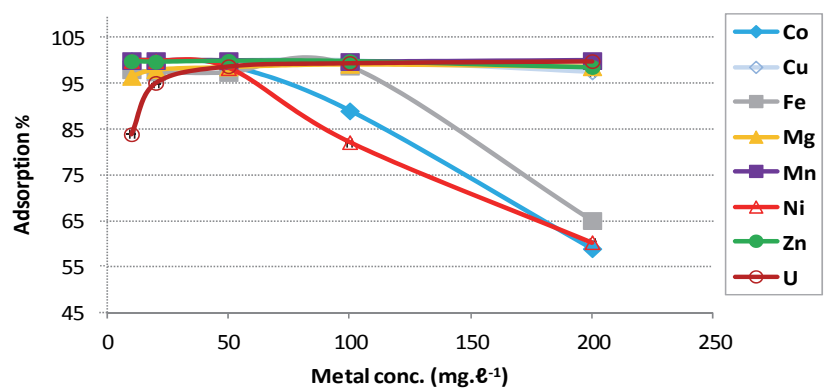

Figure 3

Dependence of metal ion adsorption on concentration at $\mathrm{pH} 2.5$

obtained in Table 1. Ni had an Ea value of $0.76 \mathrm{~kJ} \cdot \mathrm{mo}^{-1}$ (defining a diffusion mechanism) while $\mathrm{Fe}$ and Co had negative $E a$ values of -90.51 and $-2.61 \mathrm{~kJ} \cdot \mathrm{mol}^{-1}$, respectively. The negative values depict preference for low energy sites during adsorption, which could have been exhausted at 60 and $90 \mathrm{mg} \cdot \ell^{-1}$.

\section{Thermodynamic parameters}

The thermodynamic criteria for sorption are well explained by evaluation of the three important thermodynamic parameters, namely: change in enthalpy $(\Delta \mathrm{H})$, Gibbs free energy change $(\Delta G)$ and entropy change $(\Delta S)$. Net enthalpy change $(\Delta H)$ is related to $\Delta G$ and $\Delta S$ as $\Delta G=\Delta H-T(\Delta S)$. The thermodynamic parameters calculated are given in Table 1 .

In this process, changes in temperature ( $291 \mathrm{~K}$ and $303 \mathrm{~K}$ ) did not have much effect on the adsorption of the metals. The adsorption percentage of the metals ranges from 99.84 to $100 \%$, showing that this adsorbent efficiently removed the metal ions from the solution.

The trend in the Gibbs free energy shows negative values for all of the metals tested, which indicates that the adsorption process of these metals was spontaneous. A positive or a negative change in enthalpy indicates whether a reaction is endothermic or exothermic. $\Delta H^{\circ}$ values for $\mathrm{Cu}, \mathrm{Fe}$ and $\mathrm{Zn}$ are negative, implying that the process is exothermic for these ions. Most of the metals showed positive $\Delta \mathrm{H}^{\circ}$ values indicating that their adsorption was endothermic. The activation energy $(E a)$ values obtained in Table 1 show that most of the metals adsorb via physisorption, with the exception of $U$ which adsorbs by chemisorption. A reaction is classified as physisorption when the $E a$ ranges between 5 and $40 \mathrm{~kJ} \cdot \mathrm{mo}^{-1}$, whereas chemisorption has an $E a$ value between 40 and $800 \mathrm{~kJ} \cdot \mathrm{mol}^{-1}$ (Boparai et al., 2010). concentration are presented in Fig. 3. A pH of 2.5 was chosen in order to assess how efficiently adsorption would occur in acidic mine leachates.

$\mathrm{Cu}, \mathrm{Mg}, \mathrm{Mn}, \mathrm{U}$ and $\mathrm{Zn}$ showed a constant maximum adsorption as the feed concentration of each metal increased from $10 \mathrm{mg} \cdot \ell^{-1}$ to $200 \mathrm{mg} \cdot \ell^{-1}$. The adsorption of $\mathrm{Co}$ and $\mathrm{Ni}$ decreased beyond $60 \mathrm{mg} \cdot \ell^{-1}$, while that for Fe decreased beyond $90 \mathrm{mg} \cdot \ell^{-1}$. The trend is correlated to the activation energies

TABLE 1

Thermodynamic parameters for the adsorption of metals (at $291 \mathrm{~K}$ and $303 \mathrm{~K}$ ) on the BPAP silica polyamine composite

\begin{tabular}{|c|c|c|c|c|c|c|c|}
\hline \multirow[t]{2}{*}{ Metal ion } & \multirow{2}{*}{$\begin{array}{c}\text { Activation } \\
\text { energy }(E a) \\
\mathrm{kJ} \cdot \mathrm{mo}^{-1}\end{array}$} & \multicolumn{2}{|c|}{$\begin{array}{l}\text { Adsorption capacity (AC) } \\
\mathrm{mg} \cdot \mathrm{g}^{-1}\end{array}$} & \multirow[t]{2}{*}{$\begin{array}{c}\text { Enthalpy }\left(\Delta H^{\circ}\right) \\
\mathrm{kJ} \cdot \mathrm{mo}^{-1}\end{array}$} & \multicolumn{2}{|c|}{$\begin{array}{l}\text { Gibbs free energy }\left(\Delta G^{\circ}\right) \\
\mathrm{kJ} \cdot \mathrm{mo}^{-1}\end{array}$} & \multirow[t]{2}{*}{ Type of adsorption } \\
\hline & & $291 \mathrm{~K}$ & $303 \mathrm{~K}$ & & $291 \mathrm{~K}$ & $303 \mathrm{~K}$ & \\
\hline $\mathrm{Co}^{2+}$ & 14.78 & 4.405 & 4.317 & 34.04 & -13.06 & -1.5 & Physisorption \\
\hline $\mathrm{Cu}^{2+}$ & -2.613 & 4.742 & 4.751 & -6.018 & -13.06 & -13.42 & Undefined \\
\hline $\mathrm{Fe}^{2+}$ & -90.51 & 4.658 & 4.905 & -208.4 & -10.14 & -22.44 & Undefined \\
\hline $\mathrm{Mg}^{2+}$ & 5.104 & 4.954 & 4.950 & 11.76 & -28.65 & -27.95 & Physisorption \\
\hline $\mathrm{Mn}^{2+}$ & 19.792 & 4.997 & 4.996 & 45.58 & -52.48 & -49.79 & Physisorption \\
\hline $\mathrm{Ni}^{2+}$ & 0.757 & 4.383 & 4.378 & 1.744 & -2.98 & -2.87 & Diffusion \\
\hline $\mathrm{Zn}^{2+}$ & 16.04 & 4.796 & 4.983 & -369.4 & -15.39 & -37.19 & Physisorption \\
\hline $\mathrm{U}^{6+}$ & 54.61 & 4.999 & 4.999 & 125.7 & -66.4 & -58.97 & Chemisorption \\
\hline
\end{tabular}




\begin{tabular}{|l|c|c|c|c|c|c|c|}
\hline \multicolumn{7}{|c|}{ TABLE 2 } \\
\hline \multirow{2}{*}{$\begin{array}{c}\text { Time } \\
(\mathrm{min})\end{array}$} & \multicolumn{7}{|c|}{ Reaction rates for different time periods } \\
\cline { 2 - 8 } & $\mathrm{Co}^{2+}$ & $\mathrm{Fe}^{2+}$ & $\mathbf{M g}^{2+}$ & $\mathbf{M n}^{2+}$ & $\mathbf{N i}^{2+}$ & $\mathbf{Z n}^{2+}$ & $\mathrm{U}^{+6}$ \\
\hline 0 & 0 & 0 & 0 & 0 & 0 & 0 & 0 \\
\hline 10 & 5.120 & 4.440 & 0.222 & 0.007 & 0.235 & 4.420 & 4.920 \\
\hline 30 & 1.205 & 0.995 & 0.037 & 0.005 & 0.372 & 1.695 & 2.286 \\
\hline 60 & 0.293 & 0.540 & 0.003 & 0.003 & 0.341 & 0.300 & 0.090 \\
\hline 120 & 0.092 & 0.145 & 0.005 & 0.002 & 0.087 & 0.060 & 0.009 \\
\hline 180 & 0.007 & 0.087 & 0.004 & 0.001 & 0.029 & 0.008 & 0.002 \\
\hline
\end{tabular}

TABLE 3

Kinetic models at $291 \mathrm{~K}$ and $\mathrm{pH} 2.5$

\begin{tabular}{|c|c|c|c|c|c|c|c|c|c|c|c|c|c|c|c|c|}
\hline \multirow{3}{*}{$\begin{array}{l}\text { Metal } \\
\text { ion }\end{array}$} & \multicolumn{4}{|c|}{ Pseudo-first-order } & \multicolumn{4}{|c|}{ Pseudo-second order } & \multicolumn{4}{|c|}{ Elovich model } & \multicolumn{4}{|c|}{ Intraparticle diffusion } \\
\hline & $K_{1}$ & $S$ & $R^{2}$ & $\Delta q$ & $K_{2}$ & $S$ & $R^{2}$ & $\Delta q$ & $\beta$ & $a$ & $R^{2}$ & $\Delta q$ & $k_{\text {id }}$ & a & $R^{2}$ & $\Delta q$ \\
\hline & $\left(\min ^{-1}\right)$ & & & (\%) & $\begin{array}{c}\left(\mathrm{g} \cdot \mathrm{mg}^{-1} .\right. \\
\left.\mathrm{min}^{-1}\right)\end{array}$ & & & (\%) & $\begin{array}{c}* \begin{array}{c}* \\
10^{-3} \\
\left(\mathrm{~g} \cdot \mathrm{mg}^{-1}\right)\end{array} \\
\end{array}$ & $\begin{array}{l}\left(\mathbf{m g} \cdot \mathbf{g}^{-}\right. \\
\left.{ }^{1} \cdot \mathrm{min}\right)\end{array}$ & & (\%) & $\begin{array}{c}(\mathrm{mg} \cdot \mathrm{g} \\
\cdot \mathrm{min})\end{array}$ & & & (\%) \\
\hline $\mathrm{Co}^{2+}$ & 0.145 & 0.434 & 0.690 & 55.6 & 0.242 & 0.696 & 0.910 & 8.24 & 597 & 0.215 & 0.956 & 0.75 & 0.607 & 0.500 & 0.835 & 48.6 \\
\hline $\mathrm{Fe}^{2+}$ & 0.220 & 0.108 & 0.541 & 58.3 & 0.278 & 0.101 & 0.964 & 2.52 & 447 & 0.213 & 0.981 & 5.36 & 0.611 & 0.685 & 0.371 & 55.7 \\
\hline $\mathrm{Mg}^{2+}$ & 0.903 & 0.186 & 0.970 & 12.1 & 0.241 & 0.812 & 0.950 & 3.31 & 0.264 & 0.289 & 0.934 & 2.58 & 0.634 & 0.310 & 0.849 & 25.3 \\
\hline $\mathrm{Mn}^{2+}$ & 0.182 & 0.172 & 0.542 & 28.4 & 0.234 & 0.592 & 0.966 & 1.24 & 0.118 & 0.251 & 0.948 & 36.5 & 0.634 & 0.102 & 0.715 & 41.1 \\
\hline $\mathrm{Ni}^{2+}$ & 0.187 & 0.138 & 0.467 & 25.5 & 0.217 & 0.310 & 0.890 & 5.63 & 470 & 0.347 & 0.994 & 0.62 & 0.662 & 0.662 & 0.731 & 18.6 \\
\hline $\mathrm{Zn}^{2+}$ & 0.208 & 0.119 & 0.559 & 63.2 & 0.245 & 0.310 & 0.920 & 0.45 & 215 & 0.209 & 0.921 & 12.6 & 0.585 & 0.950 & 0.594 & 60.4 \\
\hline $\mathrm{U}^{6+}$ & 0.186 & 0.145 & 0.636 & 88.4 & 0.243 & 0.420 & 0.910 & 1.02 & 0.521 & 0.195 & 0.967 & 31.9 & 0.557 & 0.238 & 0.314 & 82.9 \\
\hline
\end{tabular}

$R^{2}$ : correlation coefficient; $S$ : standard error

$\mathrm{Fe}$ and $\mathrm{Cu}$ had negative values for activation energy. This could be attributed to their preference to bind to active sites with low energy. As such, adsorption of these metals occurs without an energy barrier. Their adsorption mechanism could be a combination of physisorption, chemisorption and diffusion. The $E a$ for Ni adsorption falls outside that of either chemisorption or physisorption.

The high $E a$ for $U$ is a result of ion complex formation between the uranyl ion and the phosphate ligand on the adsorbent, which occurs via the inner-sphere mechanism in which the adsorbate loses solvating water molecules (Taffet, 2004). $\mathrm{Mg}, \mathrm{Mn}$ and $\mathrm{Zn}$ adsorption is of a physisorption type, which is due to ion pair formation of the metals occurring through the outer-sphere complexes and/or as complexes that lose part of their aqueous solvation spheres, hence the low $E a$ values (Bakatula, 2012).

\section{Effect of time}

The rates of reaction for the different times studied in this experiment are given in Table 2. All of the metals displayed fast adsorption within the first $10 \mathrm{~min}$ (kinetic control), with a decrease beyond this time zone (equilibrium control). This is largely attributed to the availability of active reaction sites, which decreases with time.

\section{Adsorption kinetics}

The estimated model and related statistical parameters are reported in Table 3. Based on the linear regression $\left(R^{2}>0.95\right)$ values of the metal ions, the sorption of $\mathrm{Fe}, \mathrm{Mg}$ and $\mathrm{Mn}$ was observed to follow the pseudo second-order kinetic model. The adsorption of Co, Zn, Ni and U also followed the pseudo second-order kinetic model with a correlation coefficient between 0.890 and 0.920. Pseudo second-order kinetics is based on the assumption that sorption follows a secondorder mechanism, with chemisorption as the rate-limiting step. The rate of occupation of adsorption sites is proportional to the square of the number of unoccupied sites (Zan et al., 2012).

The experimental data for $\mathrm{Mg}$ showed good compliance with the pseudo first-order and the pseudo second-order kinetic models $\left(R^{2} \geq 0.950\right)$.

The rate constants of pseudo-second-order $\left(K_{2}\right)$ were in the range $0.217-0.278 \mathrm{~g} \cdot \mathrm{mg}^{-1} \cdot \mathrm{min}^{-1}$ and were found to be higher than those obtained for pseudo first-order kinetics, with the exception of $\mathrm{Mg}$ which had $K_{1}(0.903)>K_{2}(0.241)$. This result correlated more closely with the best fit found for the pseudo first-order kinetic model.

The Elovich kinetic parameters, $\alpha, \beta$ and correlation coefficients, are also presented in Table 3 . The correlation coefficients were in the range of 0.921-0.994. The Elovich kinetic model best defined the adsorption process for all of the metal ions studied. The coefficients $\alpha$ and $\beta$ are related to chemisorption rate and surface coverage, respectively.

The values of $k_{i d}$ were calculated from the slopes of plots for intraparticle diffusion (plots not shown here) and the $R^{2}$ values suggest that the intraparticle diffusion process was not the rate-limiting step. This was further substantiated by the fact that the plot of $q_{e}$ vs. $t^{1 / 2}$ did not pass through the origin. If the the plot of $q_{e}$ vs $t^{1 / 2}$ passes through the origin, then intraparticle diffusion is the rate-limiting step. When the plot does not pass through the origin, it is indicative of some degree of boundary layer control. This means intraparticle diffusion would not be the only rate-limiting step. Higher values of $k_{i d}$ illustrate an enhancement in the rate of adsorption and a better adsorption mechanism, which is related to an improved bonding between metal ions and the adsorbent. 


\begin{tabular}{|l|c|c|c|c|c|c|c|}
\hline \multicolumn{7}{|c|}{ TABLE 4 } \\
\multicolumn{7}{|c|}{ Adsorption parameters calculated using the Langmuir and the Freundlich isotherms } \\
\hline \multirow{2}{*}{ Metal ion } & \multicolumn{3}{|c|}{ Langmuir model } & & \multicolumn{3}{c|}{ Freundlich model } \\
\cline { 2 - 8 } & $\begin{array}{c}\mathbf{q}_{\mathbf{o}} \\
\left(\mathbf{m} \mathbf{g}^{-1}\right)\end{array}$ & $\begin{array}{c}\boldsymbol{B} \\
\left(\boldsymbol{\ell} \cdot \mathbf{m g}^{-1}\right)\end{array}$ & $\boldsymbol{R}^{\mathbf{2}}$ & $\boldsymbol{R}_{\boldsymbol{s}}$ & $\boldsymbol{K}_{\boldsymbol{f}}$ & $\boldsymbol{n}$ & $\boldsymbol{R}^{\mathbf{2}}$ \\
\hline $\mathrm{Co}^{2+}$ & 55.6 & 0.268 & 0.998 & 0.427 & 0.165 & 4.01 & 0.606 \\
\hline $\mathrm{Cu}^{2+}$ & 277.2 & 0.0157 & 0.998 & 0.928 & 0.587 & 1.82 & 0.831 \\
\hline $\mathrm{Fe}^{2+}$ & 158.4 & 0.1596 & 0.999 & 0.556 & 0.604 & 2.32 & 0.820 \\
\hline $\mathrm{Mg}^{2+}$ & 34.98 & 0.4622 & 0.182 & 0.300 & 0.387 & 1.53 & 0.342 \\
\hline $\mathrm{Mn}^{2+}$ & 125 & 0.010 & 0.999 & 0.995 & 1.257 & 1.35 & 0.962 \\
\hline $\mathrm{Ni}^{2+}$ & 204 & 0.3504 & 0.988 & 0.363 & 0.754 & 2.31 & 0.996 \\
\hline $\mathrm{Zn}^{2+}$ & 178.6 & 0.0237 & 0.986 & 0.894 & 0.483 & 8.85 & 0.766 \\
\hline $\mathrm{U}^{6+}$ & 147.2 & 0.062 & 0.909 & 0.581 & 2.705 & 5.3 & 0.982 \\
\hline
\end{tabular}

$R=$ correlation coefficient. Initial concentration of metal ion is $5 \mathrm{mg} \cdot \ell^{-1} ; R_{\mathrm{s}}=$ separation factor

\section{Adsorption isotherms}

The values of adsorption constants and correlation coefficients obtained for both adsorption models are presented in Table 4 . The Langmuir constant $(b)$ values were found to be higher for $\mathrm{Co}, \mathrm{Fe}, \mathrm{Mg}$ and Ni. Although $\mathrm{Mg}$ had the highest value for $b$, its experimental data did not fit the Langmuir isotherm. The essential characteristics of the Langmuir isotherm expressed by a dimensionless constant separation factor $R_{s}$ were in the range 0 to 1 for the adsorption of metal ions onto BPAP, thereby indicating favourable adsorption. The values for $R_{s}$ are shown in Table 4.

As seen from the table, the correlation coefficients for all the adsorbate-adsorbent systems were very high (> 95\%) for the Langmuir model, except for $\mathrm{Mg}$ and $\mathrm{U}$. The experimental data for $\mathrm{Mn}$ and $\mathrm{Ni}$ can also be described by the Freundlich model. The adsorption of $U$ is defined by the Freundlich isotherm. The experimental data for $\mathrm{Mg}$ did not fit the Freundlich model either. A good fit of the Freundlich isotherm to an adsorption system means there is almost no limit to the amount which can be adsorbed. The magnitude of the Freundlich parameter $K_{f}$ gives quantitative information on the relative adsorption affinity towards the adsorbed cation and the magnitude of the constant $1 / n$ provides information about the linearity of adsorption. Nonlinear adsorption indicates that the adsorption energy barrier increases exponentially with an increasing fraction of filled sites on the adsorbent (Schwarzenbach et al., 2003).

The magnitude of $K_{f}$ values indicate that for this adsorbent the adsorption of $\mathrm{Ni}$ and $\mathrm{Mn}$ is favoured over that of $\mathrm{Fe}, \mathrm{Mg}, \mathrm{Zn}$ and $\mathrm{Cu}$.

The value of $q_{o}$ (i.e. maximum uptake) appears to be significantly higher for $\mathrm{Cu}, \mathrm{Ni}, \mathrm{Zn}, \mathrm{Fe}$ and $\mathrm{Mn}$. The value of $1 / n$ less than unity is an indication that significant adsorption takes place at low concentrations, but that the increase in the amount adsorbed with concentration becomes less significant at higher concentrations, and vice versa (Vaishnav et al., 2011).

\section{Desorption studies}

Desorption studies help to elucidate the nature of adsorption and recycling of the spent adsorbent and the metal ions. The results for the desorption of $\mathrm{U}$ essentially showed an optimum desorption at about $0.8 \mathrm{~mol} \cdot \ell^{-1} \mathrm{Na}_{2} \mathrm{CO}_{3}$. This is expected as $\mathrm{U}$ tends to form strong complexes with carbonates (Tutu et al., 2009). The other metals were not released with this solution. Optimum desorption was achieved at $1 \mathrm{~mol} \cdot \ell^{-1} \mathrm{EDTA}$ concentration with $75 \%$ of $\mathrm{Fe}, 30 \%$ of $\mathrm{Cu}$ and $10 \%$ of $\mathrm{Mg}$. The other metals displayed $<5 \%$ desorption. At $1 \mathrm{~mol} \cdot \ell^{-1} \mathrm{H}_{2} \mathrm{SO}_{4}$ concentration, $45 \%$ of $\mathrm{Cu}$ and $20 \%$ of $\mathrm{Mg}$ were desorbed while the rest of the metals had $<5 \%$ desorption.

\section{CONCLUSIONS}

The BPAP silica polyamine composite has been shown to be an effective adsorbent for the removal of metals from aqueous solution and particularly from acidic drainages such as AMD. Adsorption kinetics are important in establishing the time zones and effective lifespanss of adsorbents and provide information on the need for regeneration. The Langmuir isotherm best described the adsorption of the metal ions studied. The pseudo second-order kinetic model as well as the Elovich model best defined the kinetic adsorption process. Thermodynamic studies were shown to be important in determining the surfacemetal reaction mechanisms. The sorption process was found to be of a physiosorption type for most of the metals, as predicted by the activation energies. While desorption results for $U$ were commendable, those for other metals were unsatisfactory, thus necessitating further exploitation of other desorbents.

\section{ACKNOWLEDGEMENTS}

The authors would like to thank the Carnegie Corporation and the Friedel Sellschop Foundation for financial support.

\section{REFERENCES}

AKCIL A and KOLDAS S (2006) Acid mine drainage (AMD): causes, treatment and case studies. J. Clean. Prod. 14 1139-1142.

ALLEN SJ, McKAY G and KHADER K (1989) Intraparticle diffusion of a basic dye during adsorption onto sphagnum peat. J. Environ. Pollut. 50 39-50.

BAKATULA EN (2012) Development of a biophysical system based on bentonite, zeolite and micro-organisms for remediating gold mine wastewaters and tailings ponds. $\mathrm{PhD}$ thesis, University of the Witwatersrand, Johannesburg. $465 \mathrm{pp}$.

BOPARAI HK, JOSEPH M and O'CARROLL DM (2010) Kinetics and thermodynamics of cadmium ion removal by adsorption onto nano zerovalent iron particles. J. Hazardous Mater. 186 458-465.

CHANDER S and MOHAN D (2001) Single component and multicomponent adsorption of metal ions by activated carbons. Colloids Surf. A 177 183-196.

COZMUTA ML, COZMUTA MA, PETER A, NICULA C, BAKATULA EN and TUTU H (2012) The influence of $\mathrm{pH}$ on the adsorption of lead by Na-clinoptilolite: Kinetic and equilibrium studies. Water SA 38 (2) 269-278. 
GÜNAY A, ARSLANKAYA E and TOSUN I (2007) Lead removal from aqueous solution by natural and pretreated clinoptilolite: Adsorption equilibrium and kinetics. J. Hazardous Mater. 146 (1-2) 362-371.

HO YS, WASE DAJ and FORESTER CF (1999) Kinetic studies of competitive heavy metal adsorption by sphagnum peat. Environ Technol. 17 441-443.

HUGHES M, MIRANDA P, NIELSEN D and ROSENBERG E (2006) Silica polyamine composites: New supramolecular materials for cation and anion recovery and remediation. Macromol. Symp. 235 161-178.

JIANG J, WU L, LI N, LUO Y, LIU L, Q. ZHAO Q, ZHANG L and CHRISTIE P (2009) Effects of multiple heavy metals contamination and repeated phytoextraction by Sedum plumbizincicola on soil microbial properties. Eur. J. Soil Biol. 46 18-26.

KAILASAM V, ROSENBERG E and NIELSEN D (2009) Characterization of surface-bound $\mathrm{Zr}(\mathrm{IV})$ and its application to removal of $\mathrm{As}(\mathrm{V})$ and As(III) from aqueous systems using phosphonic acid modified nanoporous silica polyamine composites. Ind. Eng. Chem. Res. 48 3991-4001.

KAUR R, SINGH J, KHARE R and ALI A (2012) Biosorption the possible alternative to existing conventional technologies for sequestering heavy metal ions from aqueous streams: A Review. Univers. J. Environ. Res. Technol. 2 (4) 325-335.

LAGERGREN S (1898) Zur theorie der sogenannten adsorption gelöster stoffe. Kungliga Svenska Vetenskapsakademiens. Handlingar, Band 24 (4) 1-39.

QIU H, LV L, PAN B, ZHANG Q, ZHANG W and ZHANG Q (2009) Critical review in adsorption kinetic models. J. Zhejiang Univ. Sci. A 10 (6) 716-724.

ROSENBERG E, NIELSEN D, HUGHES MA, VIALE A, GOBETTO R, FEREL J and BURTON S (2006) Structural investigations of silica polyamine composites: Surface Coverage, metal ion coordination, and ligand modification. Ind. Eng. Res. 45 6538-6539.

SCHWARZENBACH RP, GSCHWEN MP and IMBODEN DM

(2003) Environmental Organic Chemistry. John Wiley \& Sons, Inc., Hoboken, NJ. 1313 pp.

SRIVASTAVA R and RUPAINWAR DC (2011) A comparative evaluation for adsorption of dye on Neem bark and Mango bark powder. Indian J. Technol. 18 67-75.

TAFFET M (2004) Study of the reactions controlling the mobility of uranium in ground and surface water systems in contact with apatite. Lawrence Livermore National Laboratory Report, UCRL-TR-203891. University of California, Livermore, CA.

TENG H and HSIEH C (1998) Influence of surface characteristics on liquid-phase adsorption of phenol by activated carbons prepared from bituminous coal. Ind. Eng. Chem. Res. 37 (9) 3618-3624.

TUTU H, McCARTHY TS, CUKROWSKA EM, CHIMUKA L and HART R (2009) Radioactive disequilibrium and geochemical modelling as evidence of uranium leaching from gold tailings dumps in the Witwatersrand Basin. Int. J. Environ. Anal. Chem. 89 687-703.

VAISHNAV V, CHANDRA S and DAGA K (2011) Adsorption studies of $\mathrm{Zn}$ (II) ions from wastewater using Calotropis procera as an adsorbent. Int. J. Sci. Eng. Res. 2 (12) 2229-5518.

WANG XS, HUANG J, HU HQ, WANG J and QUIN Y (2007) Determination of kinetic and equilibrium parameters of the batch adsorption of $\mathrm{Ni}$ (II) from aqueous solutions by Na-mordenite. J. Hazardous Mater. 142 (1-2) 468-476.

WEBER TW and CHAKARVORTI PK (1974) Pore and solid diffusion models for fixed bed adsorbers. Am. Inst. Chem. Eng. J. 20 228-237.

ZAN F, HUO S, XI B and ZHAO X (2012) Biosorption of $\mathrm{Cd}^{2+}$ and $\mathrm{Cu}^{2+}$ on immobilized Saccharomyces cerevisiae. Front. Environ. Sci. Eng. 6 (1) 51-58.

ZHENG H, LIU D, ZHENG Y, LIANG S and LIU Z (2009) Sorption isotherm and kinetic modeling of aniline on Cr-bentonite. J. Hazardous Mater. 167 141-147. 
http://dx.doi.org/10.4314/wsa.v39i4.1 Available on website http://www.wrc.org.za

ISSN 0378-4738 (Print) = Water SA Vol. 39 No. 4 July 2013 ISSN 1816-7950 (On-line) $=$ Water SA Vol. 39 No. 4 July 2013 